\title{
Zero to Sixty: Implementing Outcomes Assessment for an Entire Organization
}

\author{
Krystal Wyatt-Baxter \\ University of Texas at Austin, USA
}

Although assessment is becoming increasingly essential to academic libraries and to higher education in general, assessment skills and experience are not usually evenly distributed throughout organizations. While a central assessment department provides consistency and leadership to an organization's assessment practices, diffusing assessment throughout an organization takes advantage of the domain expertise of its staff. Who better to assess a program than those who know it best? This paper details the process a large academic library system undertook to transform assessment from a centralized practice to a distributed program within a relatively short timeline. This narrative is intended to serve as an example of one way to implement a major assessment initiative that involves staff across an organization.

In late 2015, the University of Texas adopted a new program for institutional assessment called the "Continuous Improvement Framework." The Framework's main purpose is to guide and systematically gather assessment efforts undertaken across the university for accreditation through the Southern Association of Colleges and Schools Commission on Colleges (SACSCOC). The Framework was designed using feedback from faculty and staff involved in assessment and "focuses on use, utility and meaningful assessment practices that are sustainable over time." ${ }^{1}$ The University of Texas Libraries has a long tradition of assessment, but had not formally participated in the SACSCOC-focused institutional assessment program that existed prior to the Framework. The previous program had been designed primarily with degreegranting programs in mind, but the Framework was meant to be useful to both academic and student-service units on campus. The timeline worked out so that the UT Libraries were asked to begin participating in the Framework while simultaneously undergoing a large internal reorganization. While challenging, the crossroads of the two changes offered an opportunity to build assessment practices into the new departments and units that we were forming from the very start and served as the core initiative for our new assessment unit.

The Framework uses a traditional outcomes-based structure for assessment plans consisting of goals, measurable outcomes, work strategies designed to help achieve the outcomes, assessment methods, and targets. The UT Libraries are expected to submit plans each fall for each of our programs or departments (as defined by us). Each plan must have at least one goal and at least one aligned outcome, strategy, assessment method, and target. The following fall, we submit a report detailing our findings and identifying an actionable next step for improvement for at least one outcome. At that time, we also submit updated assessment plans for the upcoming academic year that incorporated what we learned the previous year. Beyond those requirements, we are encouraged to implement the Framework in whatever way makes the most sense for our organization. As the aforementioned reorganization was being completed, I began talking with the new directors and assistant directors about assessment expectations. I encouraged our new leadership team to think about how to assign assessment plan responsibilities within their departments and launched into a formal year-long process of working with colleagues across the libraries to write our first round of assessment plans using the following steps.

\section{Planning and Implementation Phase Workshop for Leadership}

I felt that it was important for leaders within the UT Libraries to thoroughly understand the Framework and to have an opportunity to practice thinking of their work through the structured lens of assessment planning before deciding how to assign this work within their reporting areas. I held a workshop to explain what programmatic assessment is, discuss why we were undertaking it, and detail how to get started. I walked attendees through each portion of an assessment plan and gave examples I had written for various kinds of 
work units. I then talked more about different kinds of outcomes, including process outcomes and learning outcomes, and what kinds of methods might be most likely to measure them. I gave some purposefully flawed example outcomes and had the group work together to determine how they could be improved. At this point in the workshop, I asked everyone to participate in a series of active learning exercises. I had written scenarios and asked them to develop two outcomes and accompanying assessment methods for each scenario. I then asked them to devise assessment methods, targets, and timelines for outcomes I had written.

I finished the workshop by discussing strategies for deciding how many plans they wanted in their departments (with a minimum of one) and for choosing a "point person" for each plan. I detailed what kinds of support they could expect from the assessment unit and what the internal timeline would be for delivering plan drafts. By the end of the workshop, UT Libraries leadership had a thorough understanding of what assessment plans should look like and how to approach the process within their individual departments. I asked them to follow up with me by the end of the fall semester to let me know how many plans they would have for their units and who would be responsible for communicating with me about each plan.

\section{Kick-off meetings by unit}

At the beginning of the spring semester, I scheduled face-to-face meetings with colleagues who had been designated as "point people" within each department. In these hour-long meetings, I introduced the components of the Framework, discussed the timeline we would be working on, and gave brief examples of outcomes and methods. The meetings primarily served as a chance for my colleagues to ask me questions about what would be expected of them and how I would be available to offer guidance and support. I ended each meeting by encouraging attendees to participate in a larger version of the leadership workshop that I would be offering to the entire organization.

\section{Info session and workshop}

After the kick-off meetings, I invited all of my colleagues to a combination information session and workshop designed to share information about our participation in the Framework and other assessment department initiatives. The first 30 minutes consisted of a question-and-answer session in which I introduced the Framework and addressed concerns that people had about it. During the second hour, I held the same workshop detailed above for anyone who had responsibilities for writing a plan or who was just interested in learning about programmatic assessment. Library staff were asked to self-select which portion/s of the event to attend, and both had good attendance. I made sure to stress in both that the Framework was not going to be used to judge our work, but was an opportunity for us to be proactive about continuous improvement. I allayed fears about assessment data being taken out of context or used to punish individuals or teams, and generally tried to assure everyone that our participation was a chance to show our strengths rather than a threat.

\section{Drop-in work sessions}

I scheduled drop-in sessions throughout the spring semester to encourage my colleagues working on plans to brainstorm or troubleshoot with me. For these informal sessions, I simply booked a meeting room and waited for attendees to show up. While plan participants were welcomed to schedule an individual meeting with me anytime, I thought that these more casual sessions might have a lower barrier to entry. Attendance was not overwhelming, but several colleagues did drop in with questions and concerns that I was immediately able to address.

\section{Drafts due}

I requested plan drafts by early summer to give me ample time to provide feedback and ensure plans were ready to submit to administration by the end of the summer. My colleagues were generally very conscientious about making deadlines or communicating with me when they were going to miss them so that I had to spend very little time following up to ensure that I had received what I needed. 


\section{Feedback}

I created a rubric that I used to organize feedback for each plan. I based the rubric off of the one used at the institutional level and for each portion, described characteristics of "excellent," "sufficient," and "developing" plans. At the end of the document, I included space for general comments and feedback. Using a formalized document to create and share feedback ensured that I gave objective consideration to each plan and clearly noted areas of excellence and opportunities for improvement. Once I had created a feedback document for each plan, I shared them with plan writers by email and told them to watch their email for a meeting request to discuss their plan.

\section{Implementation meetings}

After delivering feedback, I scheduled a short individual meeting with each plan writer to discuss any questions they might have and to talk about implementing their plan. My goal for these meetings was to make sure that plan writers had a timeframe in mind for each assessment method and that someone had been assigned responsibility for implementing the method. During these meetings, we also discussed how to work together on any methods, such as surveys, that they might want assistance with. In many cases, I needed to have a conversation to learn more details about the methods proposed in assessment plans. I found that many of my colleagues were very ambitious and I helped them think through implementation to make sure that their chosen methods would actually be feasible.

I also used these meetings to discuss any instances in which I had seen overlap between multiple plans or chances to combine methods to reduce work. For example, I discovered that two different units, one technology-focused and the other user-focused, had written similar outcomes pertaining to our computer labs. I called staff from both areas together to create one combined plan that could capture all of the information sought in both individual plans. I also wanted to make sure that methods that required user input were spaced out so that users were not inundated with requests for feedback from the libraries all at once.

By the end of each implementation meeting, I had filled in a spreadsheet with a description, date of implementation, and target date for finished analysis for each method. We also discussed who would be responsible for tool creation where applicable, implementation, and analysis. Library staff planned to use 142 different methods during the 2017-2018 assessment period, ranging from writing scripts to record software use to hanging posters to invite user feedback on spaces.

\section{Assessment newsletters}

I created an email list that includes library leadership and all staff members with assessment plan responsibilities and regularly sent newsletters with updates, deadline reminders, and timely assessment tips. I always reminded my colleagues of ways that I am available to support their assessment work.

\section{Plan input}

Assessment plans created as part of the Framework are shared with UT's Office of Institutional Assessment through proprietary assessment software called TracDat. At the advice of colleagues managing similar kinds of student support units on campus, I decided that I would enter all of the libraries' plans into TracDat rather than asking plan writers to attend trainings and enter their plans themselves. The goals were to reduce the burden on staff already being asked to learn a new skill, to avoid spending time on technical troubleshooting, and to ensure that plans were routed through the Assessment Department before being shared outside of the libraries to maintain consistency. Once my office had received all of the plans, a graduate research assistant entered them into TracDat in time to meet the university-wide October 1 deadline. At that point, the plans were ready to be implemented.

Throughout the 2017-2018 academic year, I checked in with plan writers by email and made myself available for consultation as needed. During this time period, I had little direct contact with most plan writers and assumed that this meant that the plans were running smoothly. 


\section{Reporting Phase}

In spring 2018, it was time to begin talking about the reporting phase for the Framework plans. Since we had a fall deadline for our findings, next steps reports, and our plans for the 2018-2019 assessment cycle, I wanted to give plan writers plenty of time to work on their deliverables.

\section{Workshop}

I invited leadership and plan writers to attend a Findings and Next Steps Workshop. The workshop covered how to write up the results from their methods into findings and how to use findings to devise next steps for program improvement.

\section{Report entry}

Plan writers were asked to submit their findings and next steps and 2018-2019 plans to me by September 1 so that I could provide feedback and request any needed edits in time to submit them in TracDat by October 1. At this point, we had completed our first full assessment cycle and were ready to embark upon the next. Since most of the plan writers retained their responsibilities and needed only minimal updates to their plans, the second cycle has been much less labor intensive than the first, without need for workshops or mandatory individual meetings. I plan to hold a gathering to celebrate the first assessment cycle and for plan writers to share successes and best practices and discuss things they would like to improve.

\section{Outcomes of First Cycle}

I was unsure of how to set my expectations for the first assessment cycle, but overall I was pleased with the level of participation. I received a report for each plan barring some that were discontinued during the year due to further organizational changes. While effort and interest varied across departments, everyone put forth the effort to try something new and ensure that we complied with Framework standards.

Multiple areas made direct changes in operations due to either the process of enacting the Framework or as a result of assessment findings. In many areas that had not been conducting formal assessments, baselines for work have now been established that will allow us to track progress over time. For example, one of our information technology groups reviewed monitoring, ticketing, and response policies and implemented more robust monitoring as a result of the assessment plan. The data that is now being collected will eventually allow for analysis that will help improve response time.

In public service units, a common change was to update trainings and improve communication with staff. Assessment practices that we routinely used before implementing the Framework assessment plans continue to show that our users are largely satisfied with our services, but methods focused on staff preparation and confidence revealed areas where we could make slight improvements. By encouraging us to focus on continuous improvement rather than user satisfaction, the Framework led us to vary our assessment practices.

One way to improve is to stop doing things that are not having the intended impact. Assessment data helped staff decide to retire a computer lab waitlist system that was not being used. Additionally, tracking use of laptops made available for students to use when attending classes in our Learning Labs helped us realize that we could reduce the number of laptops in this inventory and repurpose some for staff use. Data also led to the decision to change or discontinue events that were not well attended or did not reach their target audience. In other cases, we decided to increase outreach for underutilized resources such as lesser used specialized software that users may not realize we provide access to.

Many of the assessment reports focused more on changing assessment methods than on changing work strategies and processes to create improvement. While in many cases this was necessary, it is not sufficient. I stressed with colleagues that I did not want them to continue using methods that proved to be irrelevant or unwieldy, but I did not expect for so many "next steps" to focus on future assessment plans rather than substantive changes to programs or processes. I addressed this in feedback and will continue to do so in future trainings. 


\section{What Worked Well}

Overall it is fair to say that the first round of Framework assessment did not lead to sweeping changes, but it did teach staff how to engage in programmatic assessment and helped to engender a culture of assessment throughout the UT Libraries. I envision our Framework participation as a work in progress, and anticipate that each year will be a little better than the last. The work we did in the first year set the foundation by establishing working relationships between the assessment unit and all of the plan writers and training colleagues with diverse areas of expertise how to engage in programmatic assessment. As a result of our participation, I was asked to represent the libraries on a campus-wide working group convened to review current institutional assessment processes, make recommendations for changes, and advise the Office of Accreditation and Effectiveness on future assessment initiatives.

Flexibility and empathy were two of my most important tools in implementing programmatic assessment. I learned from the beginning that flexibility was essential. Since we were still transitioning into our reorganization when I rolled out the Framework, I made sure to let plan writers know that nothing in their plans was set in stone. Although we started the 2017-2018 cycle with 21 assessment plans, one of them became obsolete due to further reorganization, several were merged, and several more will not be continued into the 2018-2019 cycle. I consider this a result of learning what works for our organization rather than a failure. Some of my colleagues were resistant to adding assessment duties to their already full plates, and others were generally weary of assessment and had concerns that results would be used to judge them. I went to great lengths to make the process as easy as I could for my colleagues, taking on tasks such as entering their data into TracDat. I made sure to be clear about how their plans would be shared and what the institution was looking for. My goodwill went a long way in building partnerships with even my most reluctant colleagues.

\section{Moving forward}

I am confident that I learned even more than my colleagues did throughout the first year of Framework participation. Upon reflection, I will make several changes to how I manage our assessment program. First, I will set more frequent meetings with plan writers. Although meetings are time consuming, I learned that they really helped to establish a working relationship between the Assessment Unit and staff with new assessment responsibilities. Although I encouraged colleagues to reach out and schedule meetings with me as they ran into questions, I found that being proactive and setting meetings myself was a more productive approach. In the future, I will meet with every plan writer at least once during the assessment period and again before results are due to make sure everything is on track and to catch issues before it is too late to resolve them.

I will also build in more support and time for feedback on results. While I built in ample time to give feedback on assessment plans, I did not leave myself enough time to provide feedback on results before they were due to be entered into TracDat. Plan writing went so smoothly that I assumed that results would, too, but it was clear that I did not offer enough support and direction for writing up findings and devising next steps. Working more closely with plan writers during this period would have led to more actionable next steps rather than a focus on improving the assessment process itself. I will address this issue in future trainings.

Instituting large scale change in a short timeframe is not easy but can be rewarding. By distributing assessment responsibilities throughout a large library system with support from a central office, the UT Libraries are better able to leverage the expertise of our staff who are best positioned to measure success and make improvements in their own areas. Undertaking this massive project has proven beneficial to our organization both internally and in our campus relationships.

-Copyright 2019 Krystal Wyatt-Baxter 


\section{Endnote}

1. "Continuous Improvement Framework and Templates," Institutional Accreditation \& Effectiveness, accessed November 1, 2018, https://provost.utexas.edu/iae/assessment/continuous-improvementframework-templates. 